\title{
Temperature-dependent inotropic and lusitropic indices based on half-logistic time constants for four segmental phases in isovolumic left ventricular pressure-time curve in excised, cross-circulated canine heart
}

\begin{tabular}{|r|l|}
\hline Journal: & Canadian Journal of Physiology and Pharmacology \\
\hline Manuscript ID & cjpp-2015-0196.R1 \\
\hline Manuscript Type: & Article \\
\hline Date Submitted by the Author: & $29-J a n-2016$ \\
\hline Complete List of Authors: & $\begin{array}{l}\text { Mizuno, Ju; Juntendo University Faculty of Medicine, Department of } \\
\text { Anesthesiology and Pain Medicine; Okayama University Graduate School of } \\
\text { Medicine, Dentistry and Pharmaceutical Sciences, Department of } \\
\text { Cardiovascular Physiology; Kyushu University, Department of Dental } \\
\text { Anesthesiology, Faculty of Dental Science; The University of Tokyo, } \\
\text { Department of Anesthesiology, Faculty of Medicine } \\
\text { Mohri, Satoshi; Okayama University Graduate School of Medicine, Dentistry } \\
\text { and Pharmaceutical Sciences, Department of Cardiovascular Physiology; } \\
\text { Kawasaki Medical School, First Department of Physiology } \\
\text { Yokoyama, Takeshi; Kyushu University, Department of Dental } \\
\text { Anesthesiology, Faculty of Dental Science } \\
\text { Otsuji, Mikiya; The University of Tokyo, Department of Anesthesiology, } \\
\text { Faculty of Medicine } \\
\text { Arita, Hideko; JR Tokyo General Hospital, Department of Anesthesiology } \\
\text { and Pain Relief Center } \\
\text { Hanaoka, Kazuo; JR Tokyo General Hospital, Department of Anesthesiology } \\
\text { and Pain Relief Center }\end{array}$ \\
\hline Keyword: & $\begin{array}{l}\text { hyperthermia, hypothermia, inotropism, lusitropism, mono-exponential } \\
\text { time constant }\end{array}$ \\
\hline \hline
\end{tabular}


Temperature-dependent inotropic and lusitropic indices based on half-logistic time constants for four segmental phases in isovolumic left ventricular pressure-time curve in excised, cross-circulated canine heart

Ju MIZUNO ${ }^{1,2,4,5,6}$, Satoshi MOHRI ${ }^{2,3}$, Takeshi YOKOYAMA ${ }^{4,5}$ Mikiya OTSU ${ }^{5}$, Hideko ARITA ${ }^{6}$, Kazuo HANAOKA ${ }^{6}$

1 Department of Anesthesiology and Pain Medicine, Juntendo University Faculty of Medicine, Tokyo 113-8431, Japan

2 Department of Cardiovascular Physiology, Okayama University Graduate School of Medicine, Dentistry and Pharmaceutical Sciences, Okayama, 700-8558, Japan

3 First Department of Physiology, Kawasaki Medical School, Kurashiki, 701-0192, Japan

4 Department of Dental Anesthesiology, Faculty of Dental Science, Kyushu University, Fukuoka, 812-8582, Japan

5 Department of Anesthesiology, Faculty of Medicine, The University of Tokyo, Tokyo, 113-8655, Japan

6 Department of Anesthesiology and Pain Relief Center, JR Tokyo General Hospital, Tokyo, 151-8528, Japan

Short Running Title: Temperature-Dependent Half-logistic Time Constant 4 Tables and 3 Figures

Address for Correspondence; Ju Mizuno, M.D., Ph.D.

Department of Anesthesiology and Pain Medicine, Juntendo University Faculty of Medicine,

3-1-3 Hongo, Bunkyo-ku Tokyo 113-8431, Japan.

Tel: +81-3-3813-3111; Fax: +81-3-5689-3820; Email: mizuno_ju8@yahoo.co.jp 


\begin{abstract}
Varying temperature affects cardiac systolic and diastolic function and the left ventricular (LV) pressure-time curve (PTC) waveform that includes information about LV inotropism and lusitropism. Our proposed half-logistic (h-L) time constants obtained by fitting using h-L functions for four segmental phases (Phases I-IV) in the isovolumic LV PTC are more useful indices for estimating LV inotropism and lusitropism during contraction and relaxation periods than the mono-exponential (m-E) time constants at normal temperature. In this study, we investigated whether the superiority of the goodness of $\mathrm{h}-\mathrm{L}$ fits remained even at hypothermia and hyperthermia. Phases I-IV in the isovolumic LV PTCs in eight excised, cross-circulated canine hearts at $33^{\circ} \mathrm{C}, 36^{\circ} \mathrm{C}$, and $38^{\circ} \mathrm{C}$ were analyzed using $\mathrm{h}-\mathrm{L}$ and $\mathrm{m}-\mathrm{E}$ functions and the least-squares method. The h-L and m-E time constants for Phases I-IV significantly shortened with increasing temperature. Curve fitting using $\mathrm{h}-\mathrm{L}$ functions was significantly better than that using m-E functions for Phases I-IV at all temperatures. Therefore, the superiority of the goodness of $h-L$ fit vs. $m-E$ fit remained at all temperatures. As LV inotropic and lusitropic indices, temperature-dependent $\mathrm{h}-\mathrm{L}$ time constants could be more useful than m-E time constants for Phases I-IV.
\end{abstract}

Key words: hyperthermia; hypothermia; inotropism; lusitropism; mono-exponential time constant 


\section{Introduction}

It is well known that varying temperature affects cardiac systolic and diastolic functions and the left ventricular (LV) pressure-time curve (PTC) waveform that includes information about LV inotropism and lusitropism for evaluating LV performance during contraction and relaxation periods (Eucker et al. 2001, 2002). For example, hypothermia causes considerable prolongation in the LV contraction and relaxation periods, whereas hyperthermia causes considerable shortening.

Nonlinear regression analyses using the least-squares method are valuable tools for elucidating the mechanisms, summarizing information, eliminating noise, allowing speculation regarding unmeasured data, and separating the effects of multiple factors. To maximize the amount of useful information extracted from the isovolumic LV PTC, LV PTC is generally divided into two sequential phases by a boundary at the peak LV pressure (LVP): the ascending phase and descending phase, which are regarded as the contraction and relaxation phases, respectively (Mizuno et al. 2008b). The contraction phase represents the duration of the increase in the myocardial intracellular free calcium $\left(\mathrm{Ca}^{2+}\right)\left(\left[\mathrm{Ca}^{2+}\right]_{\mathrm{i}}\right)$ concentration from the sarcoplasmic reticulum (SR) by $\mathrm{Ca}^{2+}$-induced $\mathrm{Ca}^{2+}$ release, and the relaxation phase represents the duration of the decrease in $\left[\mathrm{Ca}^{2+}\right]_{i}$ concentration resulting from $\mathrm{Ca}^{2+}$ sequestration into the $\mathrm{SR}$ and $\mathrm{Ca}^{2+}$ removal from the cytoplasm to the extracellular space through the $\mathrm{Na}^{+} / \mathrm{Ca}^{2+}$ exchanger. However, the cardiac cycle does not suddenly alternate its contraction phase with its relaxation phase at one particular point, for example, the peak LVP. Thus, the contraction and relaxation phases have temporarily overlapping phases. The entire ascending phase is not the simple contraction process, and the entire descending phase is not the simple relaxation process. Therefore, we need to investigate the isovolumic LV PTC more thoroughly to understand LV contraction and relaxation functions and the relationship between contraction and relaxation periods. In our previous study, we divided the isovolumic LV PTC into four segmental phases (Phases I-IV) by boundaries at three meaningful points: the maximum of the first-order time derivative of LVP $\left(\mathrm{d} P / \mathrm{d} t_{\max }\right)$, the peak LVP, and the minimum of the first-order time derivative of LVP $\left(\mathrm{d} P / \mathrm{d} t_{\min }\right)$.

Thereafter, we found that the half-logistic ( $h-L)$ functions, which represent half-curves of symmetrical sigmoid logistic functions by a boundary at the inflection 
point, produced better fits for Phases I-IV in the isovolumic LV PTC than the mono-exponential (m-E) functions, which have been used for Phase IV, at normothermia (Mizuno et al. 2006, 2008b). Therefore, the h-L time constants obtained by fitting using h-L functions for Phases I-IV are more reliable and useful inotropic and lusitropic indices for estimating LV contraction and relaxation periods during the cardiac cycle at normothermia than the m-E time constants.

In previous studies, hypothermia-induced prolongation in the lusitropic index $m-E$ time constant obtained by fitting using the $m-E$ function for Phase IV in the isovolumic LV PTC and hyperthermia-induced shortness (Fischer et al. 2005; Greene et al. 1980; Lauri et al. 1996; Saeki et al. 2000; Tveita et al. 1998). However, we found that the $\mathrm{h}-\mathrm{L}$ function provided better fits for Phase IV in the isovolumic LV PTC than the $\mathrm{m}-\mathrm{E}$ function at any temperature (Mizuno et al. 2008a). Our proposed h-L time constant for Phase IV is more useful as a lusitropic index than the $\mathrm{m}$-E time constant, regardless of temperature.

In the present study, we investigated the potential application of the $h-L$ and $\mathrm{m}-\mathrm{E}$ functions to the analyses of Phases I, II, and III in the isovolumic LV PTC at hypothermia and hyperthermia, how temperature affects the $h-L$ and $m-E$ time constants, and whether the superiority of the goodness of $h-L$ fits vs. that of $m-E$ fits remained at different temperatures.

\section{Materials and Methods}

This study protocol was approved by the Animal Investigation Committee of Okayama University Graduate School of Medicine, Dentistry and Pharmaceutical Sciences. All procedures were conducted in conformity with the National Institutes of Health guidelines for animal care, Canadian Council on Animal Care (CCAC) Guidelines, and the Guiding Principles for Research Involving Animals and Human Beings endorsed by the American Physiological Society and the Physiological Society of Japan.

\section{Surgical preparation}

The excised, cross-circulated canine heart samples from another adult mongrel dogs were prepared as shown in Figure 1. The details of the surgical preparations are described elsewhere (Suga 1990; Suga et al.1998).

Briefly, a metabolic support dog $[20.1 \pm 5.6 \mathrm{~kg}$, mean \pm standard deviation (SD)] and a heart donor dog $(12.7 \pm 1.9 \mathrm{~kg})$ were anesthetized with pentobarbital sodium (25 $\mathrm{mg} \cdot \mathrm{kg}^{-1}$ i.v.) and fentanyl citrate $\left(0.1-0.2 \mathrm{mg} \cdot \mathrm{h}^{-1}\right.$ i.v.) after premedication with ketamine 
hydrochloride (25 $\mathrm{mg} \cdot \mathrm{kg}^{-1}$ i.m.). Each animal was intubated tracheally, ventilated with room air, and heparinized (15,000 U i.v. per support dog and 10,000 U i.v. per donor dog).

The bilateral common carotid arteries and unilateral external jugular vein of the support dog were cannulated and connected to the arterial and venous cross-circulation tubes, respectively. The chest of the donor dog was opened midsternally. The arterial and venous cross-circulation tubes from the support dog were cannulated into the left subclavian artery and the right ventricle (RV) via the right atrial appendage of the donor dog, respectively. All systemic and pulmonary vascular connections to the heart, were ligated, including the descending aorta, inferior vena cava, brachiocephalic artery, superior vena cava, azygos vein, and bilateral pulmonary hili. The metabolically supported beating heart was excised from the chest of the donor dog under continuous cross-circulation from the support dog. The coronary perfusion of the excised donor heart was not interrupted during the surgical preparation.

The left atrium of the donor heart was opened and all the LV chordae tendineae were severed. Complete atrioventricular block was created chemically $(0.2-0.5 \mathrm{ml}$ injection of $36 \%$ formaldehyde solution) or electrically (direct current of 20-30 J) with ablation of the bundle of His. A bipolar pacing electrode was placed on the upper portion of the ventricular septal endocardium via the left atrium. The LV was electrically paced at 500-millisecond intervals throughout the study, thus maintaining the heart rate at 120 beats $\cdot \min ^{-1}$.

A thin latex balloon with an unstretched volume of approximately $50 \mathrm{ml}$ was mounted on a rigid connector and placed in the LV. The connector was secured at the mitral annulus. The balloon was connected to a custom-made volume servo pump (AR-Brown, Tokyo, Japan). Both the balloon and the water housing of the servo pump were primed with water without any air bubbles. The servo pump enabled accurate measurement and precise control of the LV volume (LVV). LVP was measured by using a miniature pressure gauge (Model P-7, Konigsberg Instruments, Pasadena, CA, USA) placed inside the apical end of the balloon, processed with a DC stain amplifier, and low-pass filtered at a corner frequency of $100 \mathrm{~Hz}$ (Model 6M76, NEC San-ei, Tokyo, Japan). This corner frequency was high enough to avoid blunting the original pressure signals. An LV epicardial electrocardiogram (ECG) was recorded with a pair of screw-in electrodes to trigger data acquisition.

The systemic arterial blood pressure of the support dog served as the coronary 
perfusion pressure for the excised donor heart. Systemic arterial blood pressure was maintained at a stable level by infusing whole blood obtained from the donor dog, $6 \%$ hydroxyethylated starch solution, or methoxamine $\left(5-30 \mathrm{mg} \cdot \mathrm{h}^{-1}\right)$ as necessary. Arterial $\mathrm{pH}, \mathrm{PaCO}_{2}$, and $\mathrm{PaO}_{2}$ of the support dog were repeatedly measured with a blood gas analyzer and maintained within physiological ranges with supplemental oxygen, intravenous sodium bicarbonate, or appropriate adjustment of the ventilator setting. The LV, including the septum, weighed $81.2 \pm 12.4 \mathrm{~g}$ and the RV weighed $33.6 \pm 5.8 \mathrm{~g}$ after each experiment.

\section{Experimental protocol}

The temperature of the excised donor heart was controlled at $33^{\circ} \mathrm{C}, 36^{\circ} \mathrm{C}$, and $38^{\circ} \mathrm{C}$ by regulating the arterial blood temperature through cooling or warming of the coiled portion of the arterial cross-circulation tube in a thermostatic bath (NCB-1000, Tokyo Rika, Tokyo, Japan). The arterial blood temperature was measured with a thermistor (MTS-40030, Respiratory Support Products). In addition, the myocardial temperature was measured with a thermistor (6-F Foley catheter with thermistor, Respiratory Support Products) that was placed between the LV endocardium and the balloon via the left atrium and kept stable at $\pm 0.2^{\circ} \mathrm{C}$ during measurements. The temperature was randomly set for measurements. Hemodynamics, including LV pressure-time waveforms, was recorded after $30 \mathrm{~min}$ of equilibration in each temperature state.

\section{Data acquisition}

The LVP, LVV, and ECG signals were digitized at 2-millisecond intervals and processed on a LabVIEW (National Instruments, Austin, TX, USA)-installed computer. To suppress small noises in the digitized LVP data, the sampled LVP data were digitally smoothened by an 11-point, non-weighted moving average.

The time period of the isovolumic LV PTC was limited from the onset as the upstroke of the R wave of the ECG to the full end-point as the time when the decrease in the isovolumic LV PTC reached LV end-diastolic pressure (LVEDP) of the preceding diastole. This end-point corresponded to the time when LV developed pressure decreased to $0 \mathrm{mmHg}$. The first-order time derivative of LVP $(\mathrm{d} P / \mathrm{d} t)$ value was obtained by differentiating digitized LVP signals.

The isovolumic LV PTC was divided into Phases I-IV during the cardiac cycle by boundaries at the $\mathrm{d} P / \mathrm{d} t_{\max }$, the peak LVP, and the $\mathrm{d} P / \mathrm{dt}_{\min }$ as shown in Figure 2 . Thus, Phase $\mathrm{I}$ is the first half of the ascending phase defined as the period from the time 
corresponding to the onset of the isovolumic LV PTC to the time corresponding to $\mathrm{d} P / \mathrm{d} t_{\max }$. Phase $I I$ is the second half of the ascending phase defined as the period from the time corresponding to $\mathrm{d} P / \mathrm{d} t_{\max }$ to the time corresponding to peak LVP. Phase III is the first half of the descending phase defined as the period from the time corresponding to peak LVP to the time corresponding to $\mathrm{d} P / \mathrm{d} t_{\text {min. }}$. Phase IV is the second half of the descending phase defined as the period from the time corresponding to $\mathrm{d} P / \mathrm{d} t_{\min }$ to the time corresponding to LVEDP. Therefore, we suggest that Phase I corresponds to the early part of the contraction process; Phase II affects both the middle part of the contraction process and the early part of the relaxation process, and Phase III affects both the late part of the contraction process and the middle part of the relaxation process. Phase IV corresponds to the late part of the relaxation process.

\section{Half-Logistic ( $h-L)$ and mono-Exponential (m-E) equations}

The following $h-L$ function equations (Matsubara et al. 1995) were used to fit Phases I-IV in the isovolumic LV PTC using the least-squares method with DeltaGraph 4.0 (DeltaPoint, Monterey, CA, USA):

$$
\begin{aligned}
& P(t)=2 P_{1 \mathrm{~A}} /\left\{1+\exp \left[-\left(t-t_{\mathrm{aC}}\right) / P \tau_{1 \mathrm{~L}}\right]\right\}+P_{1 \mathrm{~B}} \\
& P(t)=2 P_{2 \mathrm{~A}} /\left\{1+\exp \left[\left(t-t_{\mathrm{aC}}\right) / P \tau_{2 \mathrm{~L}}\right]\right\}+P_{2 \mathrm{~B}} \\
& P(t)=2 P_{3 \mathrm{~A}} /\left\{1+\exp \left[-\left(t-t_{\mathrm{dC}}\right) / P \tau_{3 \mathrm{~L}}\right]\right\}+P_{3 \mathrm{~B}} \\
& P(t)=2 P_{4 \mathrm{~A}} /\left\{1+\exp \left[\left(t-t_{\mathrm{dC}}\right) / P \tau_{4 \mathrm{~L}}\right]\right\}+P_{4 \mathrm{~B}}
\end{aligned}
$$

, respectively. The $t$ is the time from the onset of the isovolumic LV PTC, $P_{1 \mathrm{~A}}, P_{2 \mathrm{~A}}, P_{3 \mathrm{~A}}$, and $P_{4 \mathrm{~A}}$ represent the $\mathrm{h}-\mathrm{L}$ amplitude constants, $P \tau_{1 \mathrm{~L}}, P \tau_{2 \mathrm{~L}}, P \tau_{3 \mathrm{~L}}$, and $P \tau_{4 \mathrm{~L}}$ represent the h- $\mathrm{L}$ time constants, and $P_{1 \mathrm{~B}}, P_{2 \mathrm{~B}}, P_{3 \mathrm{~B}}$, and $P_{4 \mathrm{~B}}$ represent the h-L nonzero asymptotes obtained by fitting with the h-L functions for Phases I, II, III, and IV, respectively. The $t_{\mathrm{ac}}$ and $t_{\mathrm{dc}}$ values are constants which represent the time corresponding to $\mathrm{d} P / \mathrm{d} t_{\max }$ and $\mathrm{d} P / \mathrm{d} t_{\min }$, respectively. It is noted that $t_{\mathrm{ac}}$ and $t_{d \mathrm{C}}$ are determined before the $h-L$ function fittings. The best-fitted $h-L$ function curves given by Eqs.1-4 change monotonically, but not in an S-shaped manner.

The following m-E function equations (Frederiksen et al. 1978; Weiss et al. 1976; Yellin et al. 1986) were used to fit Phases I-IV in the isovolumic LV PTC using the least-squares method:

$$
\begin{aligned}
& P(t)=P_{10} \exp \left[\left(t-t_{\mathrm{aC}}\right) / P \tau_{1 \mathrm{E}}\right]+P_{1 \infty} \\
& P(t)=P_{20} \exp \left[-\left(t-t_{\mathrm{aC}}\right) / P \tau_{2 \mathrm{E}}\right]+P_{2 \infty} \\
& P(t)=P_{30} \exp \left[\left(t-t_{\mathrm{dC}}\right) / P \tau_{3 \mathrm{E}}\right]+P_{3 \infty} \\
& P(t)=P_{40} \exp \left[-\left(t-t_{\mathrm{dC}}\right) / P \tau_{4 \mathrm{E}}\right]+P_{4 \infty}
\end{aligned}
$$


, respectively. The $t$ is the time from the onset of the isovolumic LV PTC, $P_{10}, P_{20}, P_{30}$, and $P_{40}$ represent the $\mathrm{m}-\mathrm{E}$ amplitude constants, $P \tau_{1 \mathrm{E}}, P \tau_{2 \mathrm{E}}, P \tau_{3 \mathrm{E}}$, and $P \tau_{4 \mathrm{E}}$ represent the m-E time constants, and $P_{1 \infty}, P_{2 \infty}, P_{3 \infty}$, and $P_{4 \infty}$ represent the m-E nonzero asymptotes obtained by fitting with the m-E functions for Phases I, II, III, and IV, respectively. The $t_{\mathrm{ac}}$ and $t_{\mathrm{dc}}$ values are constants which represent the time corresponding to $\mathrm{d} P / \mathrm{d} t_{\max }$ and $\mathrm{d} P / \mathrm{d} t_{\min }$, respectively. It is noted that $t_{\mathrm{ac}}$ and $t_{d \mathrm{c}}$ are determined before the $m-E$ function fittings.

The $\mathrm{h}-\mathrm{L}$ function equations (Eqs. 1-4) utilize the same number of parameters, i.e., three, as the m-E function equations (Eqs. 5-8).

\section{Temperature coefficient}

The temperature coefficient $\left(Q_{10}\right)$ (Hak et al. 1992; Reyes et al. 2008; Suga et al. 1988 ) is a convenient way to examine and report the temperature dependence of a process and represents the temperature sensitivity by which the rate of a reaction increases for every $10^{\circ} \mathrm{C}$ rise in temperature. $Q_{10}$ is a unitless quantity. In a typical experiment, the rate of the physiological process under investigation is measured at two different temperatures, $T_{1}$ and $T_{2}$, thus yielding the rate measurements $R_{1}$ measured at $T_{1}$ and $R_{2}$ measured at $T_{2}$, respectively. The $Q_{10}$ equation

$$
Q_{10}=\left(R_{2} / R_{1}\right)^{\left[10 /\left(T_{2}-T_{1}\right)\right]} \quad(\text { Eq. 9) }
$$

is then used to estimate the $Q_{10}$ for the process. The temperature unit must be either Celsius or Kelvin and may not be any other unit, such as Fahrenheit. Note that $T_{1}$ and $T_{2}$ do not need to be exactly $10^{\circ} \mathrm{C}$ apart to use Eq. 9. The same unit must be used for the two temperatures $T_{1}$ and $T_{2}$ at which the rate measurements are obtained. Moreover, the rate measurements $R_{1}$ and $R_{2}$ must use the same unit.

The rate may represent any measure of the progress of a process. If the rate of the reaction is completely temperature independent, it can be seen from Eq. 9 that the resulting $Q_{10}$ will be 1.0 . If the reaction rate increases with increasing temperature, $Q_{10}$ will be $>1$. Thus, the $Q_{10}$ value increases with increasing temperature dependence of a process. $Q_{10}$ is $>1$ for diffusion of ions and molecules in bulk solutions. For typical chemical reactions, such as pump, channel, and exchange, $Q_{10}$ values are $>2$. For many biological processes, particularly those that involve large-scale protein conformational changes, $Q_{10}$ values are $>2$. Many enzymes have a $Q_{10}$ of approximately 2 , which means that the rate of reaction doubles when the temperature is increased by $10^{\circ} \mathrm{C}$. Thus, $Q_{10}$ values may be used to infer mechanisms underlying the physiological process being investigated. 


\section{Statistics analysis}

The hemodynamic data, and three $\mathrm{h}-\mathrm{L}$ and three $\mathrm{m}-\mathrm{E}$ function parameter values were compared among $33^{\circ} \mathrm{C}, 36^{\circ} \mathrm{C}$, and $38^{\circ} \mathrm{C}$ by using one-way repeated measures analysis of variance (RANOVA) after Shapiro-Wilk test and Levene test. When one-way RANOVA was significant ( $F$-test, $p<0.05)$, multiple comparisons by the post hoc Scheffe's test were performed. The absolute values of the $h-L$ and $m-E$ amplitude constants were used for the comparison.

Goodness of $h-L$ and $m-E$ fits was evaluated by using the correlation coefficient $(r)$ and residual mean square (RMS). Paired Student's $t$-test was applied to the value after Fisher's Z-transformation $(Z)$ of $r: Z=1 / 2[\ln (1+r)-\ln (1-r)]$ (Snedecor and Cochran 1971). The pressure residuals, that is, the differences between the original LVP data and the best-fitted $h-L$ or $m-E$ function values at all the sampling points, were analyzed. RMS was calculated as the residual sum of squares divided by the residual degrees of freedom, that is, the number of data points analyzed minus the number of parameters in the function, i.e., three (Thompson et al. 1983a, 1983b). The h-L RMS value was compared with the m-E RMS value by using Wilcoxon's signed-rank test.

$33^{\circ} \mathrm{C}$ and $38^{\circ} \mathrm{C}$ were chose as the two temperatures $T_{1}$ and $T_{2}$ for the estimation of the $Q_{10}$ values.

All data were analyzed with Microsoft Excel 98 (Microsoft-Japan, Tokyo, Japan), Statcel (OMS, Saitama, Japan), and StatView 5.0 (SAS Institute Inc, Cary, NC, USA) software programs. The observed and calculated values were presented as the means $\pm \mathrm{SD}$. A $p$ value $<0.05$ indicated statistical significance.

\section{Results}

\section{Hemodynamic change}

Table 1 summarizes hemodynamic data for the isovolumic LV PTCs at $33^{\circ} \mathrm{C}$, $36^{\circ} \mathrm{C}$, and $38^{\circ} \mathrm{C}$ in eight excised, cross-circulated canine hearts. LVP at $\mathrm{d} P / \mathrm{d} t_{\text {max }}$, peak LVP, and LVP at $\mathrm{d} P / \mathrm{d} t_{\min }$ decreased significantly with increasing temperature. The $\mathrm{d} P / \mathrm{d} t_{\max }, \mathrm{d} P / \mathrm{d} t_{\min }$, and LVEDP did not change significantly with varying temperature. The time to peak LVP, time to $\mathrm{d} P / \mathrm{d} t_{\min }$, time to LVEDP, period of Phase II, period of Phase III, and period of Phase IV shortened significantly with increasing temperature. LVV was always controlled at $12.4 \pm 2.4 \mathrm{ml}$ at $33^{\circ} \mathrm{C}, 36^{\circ} \mathrm{C}$, and $38^{\circ} \mathrm{C}$.

\section{$\mathrm{h}-\mathrm{L}$ and $\mathrm{m}-\mathrm{E}$ function parameters}

$$
P \tau_{1 \mathrm{~L}}, P \tau_{2 \mathrm{~L}}, P \tau_{3 \mathrm{~L}} \text {, and } P \tau_{4 \mathrm{~L}} \text {, as well as } P \tau_{1 \mathrm{E}}, P \tau_{2 \mathrm{E}}, P \tau_{3 \mathrm{E}} \text {, and } P \tau_{4 \mathrm{E}} \text { shortened }
$$


significantly with increasing temperature, as shown in Figure 3. $P \tau_{1 \mathrm{~L}}$ was the shortest among four $\mathrm{h}-\mathrm{L}$ time constants at $33^{\circ} \mathrm{C}, 36^{\circ} \mathrm{C}$, and $38^{\circ} \mathrm{C}$. Similarly, $P \tau_{1 \mathrm{E}}$ was the shortest among four $\mathrm{m}-\mathrm{E}$ time constants at $33^{\circ} \mathrm{C}, 36^{\circ} \mathrm{C}$, and $38^{\circ} \mathrm{C} . P \tau_{3 \mathrm{E}}$ at $36^{\circ} \mathrm{C}$ and $38^{\circ} \mathrm{C}$ was longer than $P \tau_{4 \mathrm{E}}$.

The absolute values of $P_{1 \mathrm{~A}}, P_{2 \mathrm{~A}}, P_{4 \mathrm{~A}}, P_{10}, P_{20}$, and $P_{40}$ decreased significantly with increasing temperature, as listed in Table 2. $P_{2 \mathrm{~B}}, P_{3 \mathrm{~B}}, P_{2^{\infty}}, P_{3^{\infty}}$, and $P_{4 \infty}$ decreased significantly with increasing temperature.

\section{Goodness of $h-L$ and $m-E$ fits}

For Phases I-IV, the h-L Z values were always significantly greater than the $\mathrm{m}-\mathrm{E} Z$ values at $33^{\circ} \mathrm{C}, 36^{\circ} \mathrm{C}$, and $38^{\circ} \mathrm{C}$, as listed in Table 3 . The $\mathrm{h}-\mathrm{L}$ RMS values for Phases I-IV were always significantly smaller than the $\mathrm{m}-\mathrm{E}$ RMS values at $33^{\circ} \mathrm{C}, 36^{\circ} \mathrm{C}$, and $38^{\circ} \mathrm{C}$.

\section{Temperature coefficient}

The $Q_{10}$ values of the reciprocal values of $h-L$ and $m-E$ time constants listed in Table 4. The $Q_{10}$ values of $1 / P \tau_{1 \mathrm{~L}}, 1 / P \tau_{2 \mathrm{~L}}, 1 / P \tau_{1 \mathrm{E}}$, and $1 / P \tau_{2 \mathrm{E}}$ were between 1.0 and 2.0 , and the $Q_{10}$ values of $1 / P \tau_{3 \mathrm{~L}}, 1 / P \tau_{3 \mathrm{E}}, 1 / P \tau_{4 \mathrm{~L}}$, and $1 / P \tau_{4 \mathrm{E}}$ were $>2.0$.

\section{Discussion}

The above results demonstrated that both the $\mathrm{h}-\mathrm{L}$ and $\mathrm{m}-\mathrm{E}$ time constants for Phases I-IV in the isovolumic LV PTC significantly shortened with increasing temperature, and the superiority of the goodness of $h-L$ fits to that of $m-E$ fits remained even under hypothermic and hyperthermic conditions in the excised, cross-circulated canine heart. Our main finding indicates that the $h-L$ function is a superior model to express Phases I-IV more accurately at any temperature, and the $\mathrm{h}-\mathrm{L}$ time constants for Phases I-IV are more reliable and useful temperature-dependent LV inotropic and lusitropic indices during estimation of the LV contraction and relaxation periods of the cardiac cycle.

\section{Temperature-dependent $\mathrm{h}-\mathrm{L}$ time constants}

The time constant has been shown to prolong with decreasing temperature in basic and clinical cardiovascular research. For example, $P \tau_{4 \mathrm{E}}$ prolonged from 44.8 to $61.6 \mathrm{~ms}$ with decreasing temperature from $38^{\circ} \mathrm{C}$ to $34^{\circ} \mathrm{C}$ in the RV bypassed pig (Greene et al. 1989), from 25.8 to $41.5,78.5 \mathrm{~ms}$ with decreasing temperature from $37^{\circ} \mathrm{C}$ to $31^{\circ} \mathrm{C}, 25^{\circ} \mathrm{C}$ in the unsupported in situ canine heart (Tveita et al. 1998), and from 63 to $87,112 \mathrm{~ms}$ with decreasing temperature from $>36^{\circ} \mathrm{C}$ to between $36^{\circ} \mathrm{C}$ and $33^{\circ} \mathrm{C}$, < 
$33^{\circ} \mathrm{C}$ in the human heart (Luke et al. 1989). In our previous study, both $P \tau_{4 \mathrm{~L}}$ and $P \tau_{4 \mathrm{E}}$ prolonged with decreasing temperature from $36^{\circ} \mathrm{C}$ to $33^{\circ} \mathrm{C}, 30^{\circ} \mathrm{C}$ (Mizuno et al. 2008a). In contrast, $P \tau_{4 \mathrm{E}}$ shortens with increasing temperature. For example, $P \tau_{4 \mathrm{E}}$ shortened from 34.2 to $25.4 \mathrm{~ms}$ with increasing temperature from $36^{\circ} \mathrm{C}$ to $41^{\circ} \mathrm{C}$ in the isolated, cross-circulated canine heart (Saeki et al. 2000). In our previous study, both $P \tau_{4 \mathrm{~L}}$ and $P \tau_{4 \mathrm{E}}$ shortened with increasing temperature from $36^{\circ} \mathrm{C}$ to $38^{\circ} \mathrm{C}, 40^{\circ} \mathrm{C}$ (Mizuno et al. 2008a). Thus, $P \tau_{4 \mathrm{E}}$ prolonged linearly with cooling and recovered linearly with rewarming in the anesthetized canine (Lauri et al. 1996). A study showed that the $r$ value between $P \tau_{4 \mathrm{E}}$ and temperature was 0.91 (Fischer et al. 2005). In the present results, the $\mathrm{h}-\mathrm{L}$ and $\mathrm{m}-\mathrm{E}$ time constants for Phases I-IV prolonged with decreasing temperature and shortened with increasing temperature. Therefore, hypothermia induced significant extension of both $P \tau_{4 \mathrm{~L}}$ and $P \tau_{4 \mathrm{E}}$, and hyperthermia induced significant reduction.

The other time indices showing contraction and relaxation periods extended with decreasing temperature and decreased with increasing temperature. For example, the period from the beginning of the QRS interval of the ECG to the time corresponding to $\mathrm{d} P / \mathrm{d} t_{\max }$ prolonged from 50 to $54 \mathrm{~ms}$ with decreasing temperature from $36^{\circ} \mathrm{C}$ to $30^{\circ} \mathrm{C}$ and the period from the beginning of the QRS interval of the ECG to end-systolic maximal elastance ( $T_{\max }$ ) prolonged from 150 to $176 \mathrm{~ms}$ (Suga et al. 1988). In contrast, $T_{\text {max }}$ shortened from 155.7 to $124.0 \mathrm{~ms}$ with increasing temperature from $36^{\circ} \mathrm{C}$ to $41^{\circ} \mathrm{C}$ (Saeki et al. 2000) and shortened from 206.6 to $167.4,133.7 \mathrm{~ms}$ with increasing temperature from $30^{\circ} \mathrm{C}$ to $36^{\circ} \mathrm{C}, 40^{\circ} \mathrm{C}$ (Mikane et al. 1999). In the present study, the time to peak LVP, time to $\mathrm{dP} / \mathrm{d} t_{\mathrm{min}}$, time to LVEDP, and periods of Phases II, III, and IV shortened with increasing temperature.

In the present results, the relationship among the $\mathrm{h}-\mathrm{L}$ time constants for Phases I-IV was nearly similar to that among the $\mathrm{m}-\mathrm{E}$ time constants at $33^{\circ} \mathrm{C}, 36^{\circ} \mathrm{C}$, and $38^{\circ} \mathrm{C}$. For example, both $P \tau_{1 \mathrm{~L}}$ and $P \tau_{1 \mathrm{E}}$ were the smallest among the $\mathrm{h}-\mathrm{L}$ and $\mathrm{m}-\mathrm{E}$ time constants for Phases I-IV at all temperatures, respectively. Our study of curve fitting using the h-L function may have important implications in the analysis and evaluation for Phases I-IV in the isovolumic LV PTC at any temperature.

\section{Goodness of $\mathrm{h}-\mathrm{L}$ fit and temperature}

The superiority of the goodness of $h-L$ fit to that of $m-E$ fit for Phase IV in the isovolumic LV PTC was found in the excised, cross-circulated canine heart in 1995 (Matsubara et al. 1995). Thereafter, $P \tau_{4 \mathrm{~L}}$ has been used as a reliable and useful 
lusitropic index, in the calf (Mueller et al. 2001), in vivo canine (Mohri et al. 2001), in vivo mouse (Nagayama et al. 2007; Takimoto et al. 2004), isolated ejecting rat, guinea pig, ferret (Langer 2000; Langer 2002; Langer and Schmid 2003), excised cross-circulated rat (Abe et al. 2002), Langendorff-perfused ferret (Mohri et al. 2003), failing canine (Senzaki and Kass 2010), and failing human hearts (Senzaki et al. 1999; Shmuylovich and Kovács 2008). In our previous study, we found that the superiority of the goodness of $h-L$ fit to that of $m-E$ fit for Phase IV in the isovolumic LV PTC was consistently shown at $30^{\circ} \mathrm{C}, 33^{\circ} \mathrm{C}, 36^{\circ} \mathrm{C}, 38^{\circ} \mathrm{C}$, and $40^{\circ} \mathrm{C}$ because $P \tau_{4 \mathrm{E}}$ overestimated in hyperthermia and underestimated in hypothermia (Mizuno et al. 2008a).

Moreover, the goodness of h-L fits for Phases I-IV in the isovolumic LV PTC was consistently superior to that of $\mathrm{m}-\mathrm{E}$ fits in normothermia (Mizuno et al. 2008b). In the present study, the superiority of the goodness of $h-L$ fits to that of $m-E$ fits was demonstrated even at $33^{\circ} \mathrm{C}$ and $38^{\circ} \mathrm{C}$. The $\mathrm{h}-\mathrm{L}$ functions appear to minimize systemic bias at any temperature and provide more robust assessments of LV inotropism and lusitropism. These results enhance the general superiority of the $h-L$ time constants to the $\mathrm{m}-\mathrm{E}$ time constants for Phases I-IV, regardless of temperature.

\section{Myocardial force-time curve and temperature}

The time constant obtained by fitting using a function for the segmental phase in the myocardial force-time curve (FTC) can change with varying temperature. The m-E time constant for the second half of the descending phase, which is defined as the period from the time corresponding to the minimum of the first-order time derivative of force $\left(\mathrm{d} F / \mathrm{d} t_{\min }\right)$ to the time corresponding to the resting force level (Phase IV) in the myocardial isometric FTC $\left(F \tau_{4 \mathrm{E}}\right)$, extended with cooling and decreased with rewarming in rat RV papillary muscle (Dobrunz and Berman 1994). However, the superior of the goodness of $h-L$ fit to that of $m-E$ fit for Phase IV in the myocardial isometric FTC has been shown at $30^{\circ} \mathrm{C}$ in the papillary muscle super-fused with Tyrode solution in isolated ferret RV (Mizuno et al. 2000), rabbit RV (Mizuno et al. 2007; Baudet et al. 1999), and mouse LV (Mizuno et al. 2007) papillary muscles. Therefore, the $h-L$ time constant is more reliable than $F \tau_{4 \mathrm{E}}$ for Phase IV in the myocardial isometric FTC $\left(F \tau_{4 \mathrm{~L}}\right)$. In our previous studies, we also found that the $h-L$ functions produced better fits than the $m-E$ functions for Phases I-IV in the myocardial isometric FTC at $30^{\circ} \mathrm{C}$ in mouse LV and rabbit RV papillary muscles (Mizuno et al. 2009). Therefore, the $\mathrm{h}-\mathrm{L}$ time constants for Phases I-IV in the myocardial isometric FTC can be more reliable and useful myocardial inotropic and lusitropic indices than the $m-E$ time constants at any 
temperature.

\section{Myocardial intracellular $\mathrm{Ca}^{2+}$ concentration-time curve and temperature}

Furthermore, the time constant obtained by fitting using a function for the segmental phase in the myocardial $\left[\mathrm{Ca}^{2+}\right]_{i}-$ time curve (CaTC) can change with varying temperature. The $\mathrm{m}-\mathrm{E}$ time constant for the second half of the descending phase, which is defined as the period from the time corresponding to the minimum of the first-order time derivative of $\left[\mathrm{Ca}^{2+}\right]_{\mathrm{i}}\left(\mathrm{dCa} / \mathrm{d} t_{\min }\right)$ to the time corresponding to the resting $\left[\mathrm{Ca}^{2+}\right]_{\mathrm{i}}$ concentration (Phase IV) in the myocardial CaTC ( $\left.\mathrm{Ca} \tau_{4 \mathrm{E}}\right)$, has been used as an index for $\mathrm{Ca}^{2+}$ decline in the isovolumic LV in excised whole hearts of rats (Camacho et al. 1994; Chang et al. 1996) and in cardiomyocytes of mice (Su et al. 2003), rabbits (Bassani et al. 1994; Su et al. 2003), rats (Bassani and Noireaud 1994), canines (Su et al. 2003), and humans (Su et al. 2003). However, in our previous study, we found that the $h-L$ function produced a better fit than the $m-E$ function for Phase IV in the myocardial CaTC at $30^{\circ} \mathrm{C}$ in rabbit RV and mouse LV papillary muscles (Mizuno et al. 2007). Therefore, the $h-L$ time constant is more reliable than Ca $\tau_{4 E}$ for Phase IV in the myocardial CaTC ( $\mathrm{Ca}_{4 \mathrm{~L}}$ ). Moreover, the $\mathrm{h}-\mathrm{L}$ functions produced better fits than the $\mathrm{m}-\mathrm{E}$ functions for Phases I (Mizuno et al. 2011), II (Mizuno et al. 2013), and III (Mizuno et al. 2016) in the myocardial CaTC at $30^{\circ} \mathrm{C}$ in mouse LV papillary muscle. Therefore, the $\mathrm{h}-\mathrm{L}$ time constants for Phases I-IV in the myocardial CaTC can be more reliable and useful indices for assessing increases and decreases in myocardial $\left[\mathrm{Ca}^{2+}\right]_{i}$ than the $\mathrm{m}-\mathrm{E}$ time constants at any temperatures.

\section{Myocardial $\mathrm{Ca}^{2+}$ handling and temperature}

The time course during myocardial contraction and relaxation periods is governed by a variety of temperature-dependent myocardial intracellular $\mathrm{Ca}^{2+}$ processes (Stowe et al. 1999). A rise in myocardial $\mathrm{Ca}^{2+}$ occurs in response to hypothermia (Aasum and Larsen 1999). Cooling is known to decrease myosin adenosine triphosphatase (ATPase) activity, the $Q_{10}$ of which is between 2 and 3 , which in turn is expected to increase the chemo-mechanical efficiency of cross-bridge (CB) cycling (Suga et al. 1988).

The $Q_{10}$ value of reciprocal values of $h-L$ and $m-E$ time constants represents the rate of the physical, chemical, and biological phenomena related to inotropism and lusitropism for every $10^{\circ} \mathrm{C}$ rise in temperature and may be a useful index enabling speculation about whether the phenomenon depends on a physical, chemical, or biological process. Our present results are similar to the obtained $Q_{10}$ values from our 
previous studies (Mikane et al. 1999; Suga et al. 1988). These results suggest that $Q_{10}$ values are closely related to physical processes in Phases I and II and to one or more chemical processes in $\mathrm{Ca}^{2+}$ handling, consisting of the $\mathrm{SR} \mathrm{Ca}^{2+}$ pump, the sarcolemma $\mathrm{Na}^{+} / \mathrm{Ca}^{2+}$ exchange coupled with the $\mathrm{Na}^{+} / \mathrm{K}^{+}$pump, and the resultant mechanical contraction (Kappl and Hartung 1996; Shattock and Bers 1987) in Phases III and IV.

Simulation of myocardial relaxation suggests that the mechanoenergetics of the cooled heart integratively account for changes in cooling-decelerated ATPase-dependent SR $\mathrm{Ca}^{2+}$ sequestration and CB detachment (Mikane et al. 1997). Further, we speculate that the recirculation fraction rate of internal $\mathrm{Ca}^{2+}$ via SR becomes larger than $\mathrm{Ca}^{2+}$ extrusion with cooling and smaller than $\mathrm{Ca}^{2+}$ extrusion with warming by analyzing transient alternans decay (Mizuno et al. 2002). On the basis of contemporary reductionistic knowledge, the temperature sensitivities of all the $\mathrm{Ca}^{2+}$ transporters have been shown to be comparable among themselves.

Thus, the decreased myosin ATPase activity and CB cycling rate caused by cooling might give elongated $\mathrm{h}-\mathrm{L}$ and $\mathrm{m}-\mathrm{E}$ time constants. In contrast, the increased myosin ATPase activity and CB cycling rate caused by warming might give shortened $\mathrm{h}-\mathrm{L}$ and $\mathrm{m}-\mathrm{E}$ time constants. Therefore, the $\mathrm{Ca}^{2+}$ transient and mechanical processes during contraction and relaxation periods might become slower with cooling and faster with warming.

\section{Limitations}

The $\mathrm{h}-\mathrm{L}$ function remains an empirical model, and many mathematically equivalent models have been used to express the isovolumic LV PTC. It remains unknown whether contraction and relaxation have an underlying $h-L$ mechanism. However, our contention is that the isovolumic LV PTC (Matsubara et al. 1995; Mizuno et al. 2008b), myocardial isometric FTC (Mizuno et al. 2000, 2007), and CaTC (Mizuno et al. 2009, 2011, 2013, 2016) are characterized by an h-L mechanism. These time curves are thought to reflect the instantaneous number of attached and detached CB. Computer simulation of $\mathrm{Ca}^{2+}$ handling and $\mathrm{CB}$ kinetics has also shown that the cumulative CB attachment and detachment-time curves are reasonably well fitted using a sigmoid logistic function (Sakamoto et al. 1996). Therefore, we think that the $\mathrm{h}-\mathrm{L}$ nature reflects overall physiological manifestations or developments of LVP, myocardial force, and $\left[\mathrm{Ca}^{2+}\right]_{i}$ concentration caused by $\mathrm{CB}$ cycling. The physiological implication of the $\mathrm{h}-\mathrm{L}$ function is that the segmental time curves reflect the interaction of contractile events during contraction and relaxation periods at different temperatures. 


\section{Conclusions}

We conclude that both the $h-L$ and $m-E$ time constants obtained by fitting using the $h-L$ and $m-E$ functions for Phases I-IV in the isovolumic LV PTC shorten with increasing temperature in the excised, cross-circulated canine heart. The superiority of the goodness of $\mathrm{h}-\mathrm{L}$ fit to that of $\mathrm{m}-\mathrm{E}$ fit remained even under hypothermic and hyperthermic conditions. This main finding broadens the generality of the $h-L$ functions for comprehensive assessment of Phases I-IV at any temperature. The temperature-dependent $\mathrm{h}-\mathrm{L}$ time constants are more reliable and useful LV inotropic and lusitropic indices for estimating LV contraction and relaxation during the cardiac cycle with varying temperature. This approach may help gain better insight into the logic of integration in LV inotropism and lusitropism under different temperature conditions.

\section{Authors' contributions}

The work presented here was carried out in collaboration between all authors. Ju Mizuno defined the research theme, designed methods and experiments, carried out the laboratory experiments, analyzed the data, interpreted the results, and wrote the manuscript. Satoshi Mohri designed methods and experiments, and carried out the laboratory experiments. Takeshi Yokoyama, Mikiya Otsuji, Hideko Arita, and Kazuo Hanaoka discussed analyses, interpretation, and presentation. All authors have contributed to, seen and approved the manuscript.

\section{Acknowledgments}

We thank Drs. Junichi Araki, Hiromi Matsubara, Juichiro Shimizu, Shunsuke Suzuki, Takeshi Mikane, Terumasa Morita, Kunihisa Kohno, and Hiroyuki Suga for their excellent advice and support and thank Mr. Kimikazu Hosokawa for animal supply and care.

\section{Conflicts of interest}

The authors declare that they have no conflicts of interest in this work. 


\section{References}

Aasum, E., and Larsen, T.S. 1999. Different tolerance to hypothermia and rewarming of isolated rat and guinea pig hearts. Cryobiology, 38(3):243-249. doi: 10.1006/cryo.1999.2165. PMID: 10328914.

Abe, T., Ohga, Y., Tabayashi, N., Kobayashi, S., Sakata, S., Misawa, H., et al. 2002. Left ventricular diastolic dysfunction in type 2 diabetes mellitus model rats. Am. J. Physiol. 282(1):H138-148. PMID: 11748057.

Bassani, J.W.M., Bassani, R.A., and Bers, D.M. 1994. Relaxation in rabbit and rat cardiac cells: species-dependent differences in cellular mechanisms. J. Physiol. 476(2):279-293. doi: 10.1113/jphysiol.1994.sp020130. PMID: 8046643.

Baudet, S., and Noireaud, J. 1999. Pharmacologic evaluation of isometric contraction-relaxation coupling indexes in rabbit ventricular muscle. J. Pharmacol. Toxicol. Methods. 42(1):21-30. PMID: 10715600.

Camacho, S.A., Brandes, R., Figueredo, V.M., and Weiner, M.W. 1994. Ca ${ }^{2+}$ transient decline and myocardial relaxation are slowed during low flow ischemia in rat hearts. J. Clin. Invest. 93(3):951-957. doi: 10.1172/JCI117101. PMID: 8132781.

Chang, K.C., Schreur, J.H., Weiner, M.W., and Camacho, S.A. 1996. Impaired Ca ${ }^{2+}$ handling is an early manifestation of pressure-overload hypertrophy in rat hearts. Am. J. Physiol. 271(1 Pt 2):H228-H234. PMID: 8760179.

Dobrunz, L.E., and Berman, M.R. 1994. Effect of temperature on $\mathrm{Ca}^{2+}$-dependent and mechanical modulators of relaxation in mammalian myocardium. J. Mol. Cell. Cardiol. 26(2):243-250. doi: 10.1006/jmcc.1994.1027. PMID: 8006985.

Eucker, S.A., Lisauskas, J.B., Singh, J., and Kovács, S.J. 2001. Phase plane analysis of left ventricular hemodynamics. J. Appl. Physiol. (1985.), 90(6):2238-2244. PMID: 11356788.

Eucker, S.A., Lisauskas, J., Courtois, M.R., and Kovács, S.J. 2002. Analysis of left ventricular hemodynamics in physiological hyperspace. J. Appl. Physiol. (1985.), 92(1):323-330. doi: 10.1152/japplphysiol.00560.2001. PMID: 11744675.

Fischer, U.M., Cox, C.S., Jr, Laine, G.A., Mehlhorn, U., and Allen, S.J. 2005. Mild hypothermia impairs left ventricular diastolic but not systolic function. J. Invest. Surg. 18(6):291-296. doi: 10.1080/08941930500327047. PMID: 16319049.

Frederiksen, J.W., Weiss, J.L., Weisfeldt, M.L. 1978. Time constant of isovolumic pressure fall: determinants in the working left ventricle. Am. J. Physiol. 235(6):H701-706. PMID: 736158. 
Greene, P.S., Cameron, D.E., Mohlala, M.L., Dinatale, J.M., and Gardner, T.J. 1989. Systolic and diastolic left ventricular dysfunction due to mild hypothermia. Circulation, 80(5 Pt 2):III44-48. PMID: 2805306.

Hak, J.B., van Beek, J.H., van Wijhe, M.H., and Westerhof, N. 1992. Influence of temperature on the response time of mitochondrial oxygen consumption in isolated rabbit heart. J. Physiol. 447:17-31. PMID: 1593446

Kappl, M., and Hartung, K. 1996. Rapid charge translocation by the cardiac $\mathrm{Na}^{+}-\mathrm{Ca}^{2+}$ exchanger after a $\mathrm{Ca}^{2+}$ concentration jump. Biophys. J. 71(5):2473-2485. doi: 10.1016/S0006-3495(96)79441-9. PMID: 8913587.

Langer, S.F. 2000. Four-parametric non-linear regression fit of isovolumic relaxation in isolated ejecting rat and guinea pig hearts. Jpn. J. Physiol. 50(1):101-113. doi: 10.2170/jjphysiol.50.101. PMID: 10866702.

Langer, S.F. 2002. Differential laws of left ventricular isovolumic pressure fall. Physiol, Res. 51(1):1-15. PMID: 12071284.

Langer, S.F., and Schmid, H.D. 2003. Influence of preload on left ventricular relaxation in isolated ejecting hearts during myocardial depression. Exp. Clin. Cardiol. 8(2):83-90. PMID: 19641655.

Lauri, T., Timisjarvi, J., and Saukko, P. 1996. Influence of ethanol on circulation in surface-induced hypothermia and subsequent rewarming. Alcohol, 13(2):117-123. doi: 10.1016/0741-8329(95)02022-5. PMID: 8814644.

Luke, R.A., Gillbe, C.E., Bonser, R.S., Paneth, M., Somerset, D., Thomas, J., et al. 1989. Effect of temperature on rate of left ventricular pressure fall in humans. $\mathrm{Br}$. Heart J. 61(5):426-431. PMID: 2736194.

Matsubara, H., Takaki, M., Yasuhara, S., Araki, J., and Suga, H. 1995. Logistic time constant of isovolumic relaxation pressure-time curve in the canine left ventricle: better alternative to exponential time constant. Circulation, 92(8):2318-2326. doi: 10.1161/01.CIR.92.8.2318. PMID: 7554217.

Mikane, T., Araki, J., Kohno, K., Nakayama, Y., Suzuki, S., Shimizu, J., et al. 1997. Mechanism of constant contractile efficiency under cooling inotropy of myocardium: simulation. Am. J. Physiol. 273(6 Pt 2):H2891-2898. PMID: 9435629.

Mikane, T., Araki, J., Suzuki, S., Mizuno, J., Shimizu, J., Mohri, S., et al. 1999. O $_{2}$ cost of contractility but not of mechanical energy increases with temperature in canine left ventricle. Am. J. Physiol. 277(1 Pt 2):H65-73. PMID: 10409183.

Mizuno, J., Araki, J., Mikane, T., Mohri, S., Imaoka, T., Matsubara, H., et al. 2000. 
Logistic time constant of isometric relaxation force curve of ferret ventricular papillary muscle: reliable index of lusitropism. Jpn. J. Physiol. 50(5):479-487. doi: 10.2170/jjphysiol.50.479. PMID: 11120914.

Mizuno, J., Araki, J., Suzuki, S., Mohri, S., Mikane, T., Shimizu, J., et al. 2002. Temperature-dependent of postextrasystolic potentiation and $\mathrm{Ca}^{2+}$ recirculation fraction in canine hearts. Am. J. Physiol. 282(2):H403-413. doi: 10.1152/ajpheart.00427.2001. PMID: 11788386.

Mizuno, J., Mohri, S., Shimizu, J., Suzuki, S., Mikane, T., Araki, J., et al. 2006. Starling-effect-independent lusitropism index in canine left ventricle: logistic time constant. Anesth. 102(4):1032-1039. Analg. doi: 10.1213/01.ane.0000202537.19646.10. PMID: 16551893.

Mizuno, J., Otsuji, M., Takeda, K., Yamada, Y., Arita, H., Hanaoka, K., et al. 2007. Superior logistic model for decay of $\mathrm{Ca}^{2+}$ transient and isometric relaxation force curve in rabbit and mouse papillary muscles. Int. Heart J. 48(2):215-232. doi: 10.1536/ihj.48.215. PMID: 17409587.

Mizuno, J., Matsubara, H., Mohri, S., Shimizu, J., Suzuki, S., Mikane, T., et al. 2008. Half-logistic time constant: a more reliable lusitropic index than monoexponential time constant regardless of temperature in canine left ventricle. Can. J. Physiol. Pharmacol. 86(3):78-87. doi: 10.1139/y08-001. PMID: 18418434.

Mizuno, J., Shimizu, J., Mohri, S., Araki, J., Hanaoka, K., and Yamada, Y. 2008. Hypovolemia does not affect speed of isovolumic left ventricular contraction and relaxation in excised canine heart. Shock, 29(3):395-401. doi: 10.1097/SHK.0b013e3181454587. PMID: 17693939.

Mizuno, J., Morita, S., Otsuji, M., Arita, H., Hanaoka, K., Akins, R.E., et al. 2009. Half-logistic time constants as inotropic and lusitropic indices for four sequential phases of isometric tension curves in isolated rabbit and mouse papillary muscles. Int. Heart J. 50(3):389-404. doi: 10.1536/ihj.50.389. PMID: 19506342.

Mizuno, J., Hanaoka, K., Otsuji, M., Arita, H., Sakamoto, H., Fukuda, S., et al. 2011. Calcium-induced calcium release from the sarcoplasmic reticulum can be evaluated with a half-logistic function model in aequorin-injected cardiac muscles. J. Anesth. 25(6):831-838. doi: 10.1007/s00540-011-1234-0. PMID: 21979103.

Mizuno, J., Otsuji, M., Hanaoka, K., Arita, H., and Yokoyama, T. 2013. Intracellular Ca ${ }^{2+}$ transient Phase II can be assessed by half-Logistic function model in isolated aequorin-injected mouse left ventricular papillary muscle. Acta. Cardiol. Sin. 
29(4):328-338. PMID: 27122726.

Mizuno, J., Otsuji, M., Yokoyama, T., Arita, H., and Hanaoka, K. 2016. Half-Logistic function model for first half of descending phase of cardiomyocyte cytoplasmic $\mathrm{Ca}^{2+}$ concentration $\left(\left[\mathrm{Ca}^{2+}\right]_{\mathrm{i}}\right)$-Time curve (CaTCIII) in isolated aequorin-injected mouse left ventricular papillary muscle. Acta. Cardiol. Sin. 32(1): 65-74. PMID: 27122933

Mohri, S., He, K.L., Dickstein, M., Mika, Y., Shimizu, J., Shemer, I., et al. 2002. Cardiac contractility modulation by electric currents applied during the refractory period. Am. J. Physiol. 282(5):H1642-1647. doi: 10.1152/ajpheart.00959.2001. PMID: 11959626.

Mohri, S., Shimizu, J., Mika, Y., Shemer, I., Wang, J., Ben-Haim, S., et al. 2003. Electric currents applied during refractory period enhance contractility and systolic calcium in the ferret heart. Am. J. Physiol. 284(4):H1119-1123. doi: 10.1152/ajpheart.00378.2002. PMID: 12446280.

Mueller, X.M., Tevaearai, H.T., Tucker, O., Boone, Y., and von Segesser, L.K. 2001. Reshaping the remodelled left ventricle: a new concept. Eur. J. Cardiothorac. Surg. 20(4):786-791. doi: 10.1016/S1010-7940(01)00854-5. PMID: 11574226.

Nagayama, T., Takimoto, E., Sadayappan, S., Mudd, J.O., Seidman, J.G., Robbins, J., et al. 2007. Control of in vivo left ventricular [correction] contraction/relaxation kinetics by myosin binding protein C: protein kinase A phosphorylation dependent and independent regulation. Circulation, 116(21):2399-2408. doi: 10.1161/CIRCULATIONAHA.107.706523. PMID: 17984378.

Reyes, B.A., Pendergast, J.S., and Yamazaki, S. 2008. Mammalian peripheral circadian oscillators are temperature compensated. J. Biol. Rhythms. 23(1):95-98. doi: 10.1177/0748730407311855. PMID: 18258762.

Saeki, A., Goto, Y., Hata, K., Takasago, T., Nishioka, T., and Suga, H. 2000. Negative inotropism of hyperthermia increases oxygen cost of contractility in canine hearts. Am. J. Physiol. 279(6):H2855-2864. doi: 10.1016/0741-8329(95)02022-5. PMID: 11087241.

Sakamoto, T., Matsubara, H., Hata, Y., Shimizu, J., Araki, J., Takaki, M., et al. 1996. Logistic character of myocardial twitch force curve: simulation. Heart Vessels. 11(4):171-179. doi: 10.1007/BF02559989. PMID: 9119806.

Senzaki, H., Fetics, B., Chen, C.H., and Kass, D.A. 1999. Comparison of ventricular pressure relaxation assessments in human heart failure: quantitative influence on 
load and drug sensitivity analysis. J. Am. Coll. Cardiol. 34(5):1529-1536. doi: 10.1016/S0735-1097(99)00362-9. PMID: 10551703.

Senzaki, H., and Kass, D.A. 2010. Analysis of isovolumic relaxation in failing hearts by monoexponential time constants overestimates lusitropic change and load dependence: mechanisms and advantages of alternative logistic fit. Circ. Heart Fail. 3(2):268-276. doi: 10.1161/CIRCHEARTFAILURE.109.865592. PMID: 20035066.

Shattock, M.J., and Bers, D.M. 1987. Inotropic response to hypothermia and the temperature-dependence of ryanodine action in isolated rabbit and rat ventricular muscle: implications for excitation-contraction coupling. Circ. Res. 61(6):761-771. doi: 10.1161/01.RES.61.6.761. PMID: 3677335.

Shmuylovich, L., and Kovács, S.J. 2008. Stiffness and relaxation components of the exponential and logistic time constants may be used to derive a load-independent index of isovolumic pressure decay. Am. J. Physiol. 295(6):H2551-2559. doi: 10.1152/ajpheart.00780.2008. PMID: 18952715.

Snedecor, G.W., and Cochran, W.G. Statistical Methods. 6th ed. Ames, lowa: lowa State Univ Press, 1971, pp185.

Stowe, D.F., Fujita, S., An, J., Paulsen, R.A., Varadarajan, S.G., and Smart, S.C. 1999. Modulation of myocardial function and $\left[\mathrm{Ca}^{2+}\right]$ sensitivity by moderate hypothermia in guinea pig isolated hearts. Am. J. Physiol. 277(6 Pt 2):H2321-2332. PMID: 10600852.

Su, Z., Li, F., Spitzer, K.W., Yao, A., Ritter, M., and Barry, W.H. 2003. Comparison of sarcoplasmic reticulum $\mathrm{Ca}^{2+}$-ATPase function in human, dog, rabbit, and mouse ventricular myocytes. J. Mol. Cell. Cardiol. 35(7):761-767. doi: 10.1016/S0022-2828(03)00119-6. PMID: 12818566.

Suga, H., Goto, Y., Igarashi, Y., Yasumura, Y., Nozawa, T., Futaki, S,, et al. 1988. Cardiac cooling increases $\mathrm{E}_{\max }$ without affecting relation between $\mathrm{O}_{2}$ consumption and systolic pressure-volume area in dog left ventricle. Circ. Res. 63(1):61-71. doi: 10.1161/01.RES.63.1.61. PMID: 3383383.

Suga, H. 1990. Ventricular energetics. Physiol. Rev. 70(2):247-277. PMID: 2181496.

Takimoto, E., Soergel, D.G., Janssen, P.M., Stull, L.B., Kass, D.A., et al. 2004. Frequency- and afterload-dependent cardiac modulation in vivo by troponin I with constitutively active protein kinase A phosphorylation sites. Circ. Res. 94(4):496-504. doi: 10.1161/01.RES.0000117307.57798.F5. PMID: 14726477. 
Thompson, D.S., Waldron, C.B., Coltart, D.J., Jenkins, B.S., and Webb-Peploe, M.M. 1983. Estimation of time constant of left ventricular relaxation. Br. Heart J. 49(3):250-258. PMID: 6830661.

Thompson, D.S., Wilmshurst, P., Juul, S.M., Waldron, C.B., Jenkins, B.S., Coltart, D.J., et al. 1983. Pressure-derived indices of left ventricular isovolumic relaxation in patients with hypertrophic cardiomyopathy. Br. Heart J. 49(3):259-267. PMID: 6681978.

Tveita, T., Ytrehus, K., Myhre, E.S., and Hevroy, O. 1998. Left ventricular dysfunction following rewarming from experimental hypothermia. J. Appl. Physiol. 85(6):2135-2139. PMID: 9843536.

Weiss, J.L., Frederiksen, J.W., and Weisfeldt, M.L. 1976. Hemodynamic determinants of the time-course of fall in canine left ventricular pressure. J. Clin. Invest. 58(3):751-760. doi: 10.1172/JCI108522. PMID: 956400.

Yellin, E.L., Hori, M., Yoran, C., Sonnenblick, E.H., Gabbay, S., Frater, R.W.M. 1986. Left ventricular relaxation in the filling and nonfilling intact canine heart. Am. J. Physiol. 250(4 Pt 2):H620-629. PMID: 3963218. 
Figure 1. Excised, cross-circulated canine heart model. ECG, electrocardiogram; LVP, left ventricular pressure; LVV, left ventricular volume.

Figure 2. Phases I-IV in the isovolumic left ventricular (LV) pressure-time curve (PTC). $\mathrm{d} P / \mathrm{d} t_{\max }$ is the maximum of the first-order time derivative of LV pressure (LVP). $\mathrm{d} P / \mathrm{d} t_{\min }$ is the minimum of the first-order time derivative of LVP. LVEDP is the LV end-diastolic pressure. Phase $I$ is the first half of the ascending phase defined as the period from the time corresponding to the onset of the isovolumic LV PTC to the time corresponding to $\mathrm{d} P / \mathrm{d} t_{\max }$. Phase $\mathrm{II}$ is the second half of the ascending phase defined as the period from the time corresponding to $\mathrm{d} P / \mathrm{d} t_{\max }$ to the time corresponding to the peak LVP. Phase III is the first half of the descending phase defined as the period from the time corresponding to the peak LVP to the time corresponding to $\mathrm{d} P / \mathrm{d} t_{\mathrm{min}}$. Phase IV is the second half of the descending phase defined as the period from the time corresponding to $\mathrm{d} P / \mathrm{d} t_{\min }$ to the time corresponding to LVEDP.

Figure 3. Half-logistic (h-L) and mono-exponential (m-E) time constants for Phases I-IV in the isovolumic left ventricular (LV) pressure-time curves (PTCs) at $33^{\circ} \mathrm{C}, 36^{\circ} \mathrm{C}$, and $38^{\circ} \mathrm{C}$. Values indicate the mean $\pm S D$ in eight excised, cross-circulated canine hearts. $A$, B, C, and D show h-L (black squares) and $m-E$ (white circles) time constants for Phase I, $\mathrm{II}$, III, and IV, respectively. ${ }^{*}, p<0.05$ and ${ }^{* *}, p<0.001$ vs. $33^{\circ} \mathrm{C}$. †, $p<0.05$ and $\dagger \dagger, p<$ 0.001 vs. Phase II. ‡, $p<0.05$, and $\ddagger \ddagger, p<0.001$ vs. Phase III. П, $p<0.05$ and Пा, $p<$ 0.001 vs. Phase IV. 
Table 1. Hemodynamic data for the isovolumic left ventricular (LV) pressure-time curves (PTCs) at $33^{\circ} \mathrm{C}, 36^{\circ} \mathrm{C}$, and $38^{\circ} \mathrm{C}$.

\begin{tabular}{|c|c|c|c|}
\hline & \multicolumn{3}{|c|}{ Temperature $\left({ }^{\circ} \mathrm{C}\right)$} \\
\hline & 33 & 36 & 38 \\
\hline LVP at onset $(\mathrm{mmHg})$ & $-0.8 \pm 7.0$ & $-1.6 \pm 7.1$ & $-1.0 \pm 7.2$ \\
\hline LVP at $\mathrm{d} P / \mathrm{d} t_{\max }(\mathrm{mmHg})$ & $29.7 \pm 9.9$ & $26.5 \pm 9.4$ & $23.9 \pm 7.8^{*}$ \\
\hline Peak LVP (mmHg) & $78.0 \pm 16.4$ & $68.2 \pm 14.8^{\star}$ & $60.6 \pm 18.3^{* *}$ \\
\hline LVP at $\mathrm{d} P / \mathrm{d} t_{\min }(\mathrm{mmHg})$ & $39.8 \pm 16.7$ & $31.9 \pm 8.7$ & $29.5 \pm 11.3^{*}$ \\
\hline LVEDP (mmHg) & $-0.8 \pm 7.2$ & $-1.8 \pm 7.4$ & $-1.4 \pm 7.4$ \\
\hline Time to $\mathrm{d} P / \mathrm{d} t_{\max }(\mathrm{ms})$ & $80.8 \pm 14.6$ & $79.3 \pm 8.5$ & $73.8 \pm 7.5$ \\
\hline Time to peak LVP (ms) & $196.3 \pm 17.0$ & $181.0 \pm 11.1$ & $165.0 \pm 16.2^{*}$ \\
\hline Time to $\mathrm{d} P / \mathrm{d} t_{\min }(\mathrm{ms})$ & $335.0 \pm 28.3$ & $293.8 \pm 26.9^{* *}$ & $260.3 \pm 29.9^{* *} \#$ \\
\hline Time to LVEDP (ms) & $494.5 \pm 12.4$ & $448.3 \pm 36.7^{*}$ & $404.5 \pm 44.3^{* *} \#$ \\
\hline Period of Phase I (ms) & $80.8 \pm 14.6$ & $79.3 \pm 8.6$ & $75.3 \pm 8.7$ \\
\hline Period of Phase II (ms) & $115.5 \pm 16.8$ & $101.8 \pm 13.2^{*}$ & $91.3 \pm 13.7^{* *}$ \\
\hline Period of Phase III (ms) & $138.8 \pm 29.8$ & $112.8 \pm 17.2^{*}$ & $95.3 \pm 18.8^{* \star \#}$ \\
\hline Period of Phase IV (ms) & $159.5 \pm 27.0$ & $154.5 \pm 17.5$ & $144.3 \pm 33.0^{*}$ \\
\hline $\mathrm{d} P / \mathrm{d} t_{\max }\left(\mathrm{mmHg} \mathrm{s}^{-1}\right)$ & $752.5 \pm 155.0$ & $751.5 \pm 189.0$ & $702.9 \pm 208.2$ \\
\hline $\mathrm{d} P / \mathrm{d}_{\min }\left(\mathrm{mmHg} \mathrm{s} \mathrm{s}^{-1}\right)$ & $-492.0 \pm 124.1$ & $-554.3 \pm 170.4$ & $-566.7 \pm 206.5$ \\
\hline
\end{tabular}

Values indicate the means \pm SD in eight excised, cross-circulated canine hearts. LVP is LV pressure. $\mathrm{d} P / \mathrm{d} t_{\max }$ is the maximum of the first-order time derivative of LVP. LVEDP is LV end-diastolic pressure. $\mathrm{d} P / \mathrm{d} t_{\min }$ is the minimum of the first-order time derivative of LVP.

${ }^{*} p<0.05$ vs. $33^{\circ} \mathrm{C}$.

${ }^{* *} p<0.001$ vs. $33^{\circ} \mathrm{C}$.

$\# p<0.05$ vs. $36^{\circ} \mathrm{C}$. 
Table 2. Half-logistic (h-L) and mono-exponential (m-E) amplitude constants and $h-L$ and $\mathrm{m}-\mathrm{E}$ nonzero asymptotes obtained by fitting using $\mathrm{h}-\mathrm{L}$ and $\mathrm{m}-\mathrm{E}$ functions for Phases I-IV in the isovolumic left ventricular (LV) pressure-time curves (PTCs) at $33^{\circ} \mathrm{C}, 36^{\circ} \mathrm{C}$, and $38^{\circ} \mathrm{C}$

\begin{tabular}{|c|c|c|c|}
\hline & \multicolumn{3}{|c|}{ Temperature $\left({ }^{\circ} \mathrm{C}\right)$} \\
\hline & 33 & 36 & 38 \\
\hline \multicolumn{4}{|l|}{ Phase I } \\
\hline$P_{1 \mathrm{~A}}(\mathrm{mmHg})$ & $32.6 \pm 10.3$ & $29.9 \pm 8.4$ & $26.6 \pm 6.4^{*}$ \\
\hline$P_{10}(\mathrm{mmHg})$ & $36.0 \pm 10.9$ & $32.7 \pm 9.0$ & $29.2 \pm 7.0^{\star}$ \\
\hline$P_{1 \mathrm{~B}}(\mathrm{mmHg})$ & $-2.3 \pm 6.7$ & $-2.7 \pm 7.0$ & $-2.2 \pm 7.0$ \\
\hline$P_{100}(\mathrm{mmHg})$ & $-4.7 \pm 6.4$ & $-4.5 \pm 6.9$ & $-3.9 \pm 6.9$ \\
\hline \multicolumn{4}{|l|}{ Phase II } \\
\hline$P_{2 \mathrm{~A}}(\mathrm{mmHg})$ & $-54.7 \pm 7.6$ & $-45.8 \pm 8.9$ & $-40.8 \pm 14.2^{*}$ \\
\hline$P_{20}(\mathrm{mmHg})$ & $-64.0 \pm 10.2$ & $-52.7 \pm 10.3$ & $-47.2 \pm 16.3^{*}$ \\
\hline$P_{2 B}(\mathrm{mmHg})$ & $83.8 \pm 15.3$ & $72.1 \pm 15.5^{*}$ & $64.4 \pm 19.4^{* *}$ \\
\hline$P_{2 \infty}(\mathrm{mmHg})$ & $92.0 \pm 15.9$ & $77.9 \pm 16.2^{*}$ & $69.9 \pm 21.0^{* *}$ \\
\hline \multicolumn{4}{|l|}{ Phase III } \\
\hline$P_{3 \mathrm{~A}}(\mathrm{mmHg})$ & $-43.4 \pm 9.4$ & $-40.7 \pm 9.9$ & $-26.7 \pm 26.0$ \\
\hline$P_{30}(\mathrm{mmHg})$ & $-50.8 \pm 11.8$ & $-47.6 \pm 11.5$ & $-41.1 \pm 10.3$ \\
\hline$P_{3 \mathrm{~B}}(\mathrm{mmHg})$ & $82.8 \pm 16.4$ & $72.3 \pm 15.9^{*}$ & $64.2 \pm 19.2^{* *}$ \\
\hline$P_{3 \infty}(\mathrm{mmHg})$ & $89.2 \pm 16.9$ & $78.2 \pm 17.1^{*}$ & $69.4 \pm 20.6^{* *}$ \\
\hline \multicolumn{4}{|l|}{ Phase IV } \\
\hline$P_{4 \mathrm{~A}}(\mathrm{mmHg})$ & $43.7 \pm 17.2$ & $35.2 \pm 9.2$ & $32.2 \pm 11.8^{*}$ \\
\hline$P_{40}(\mathrm{mmHg})$ & $49.0 \pm 18.9$ & $38.4 \pm 10.0^{*}$ & $35.1 \pm 12.6^{\star *}$ \\
\hline$P_{4 \mathrm{~B}}(\mathrm{mmHg})$ & $-3.3 \pm 6.3$ & $-2.9 \pm 7.6$ & $-2.3 \pm 7.7$ \\
\hline$P_{4 \infty}(\mathrm{mmHg})$ & $-7.2 \pm 5.4$ & $-4.6 \pm 7.9$ & $-3.9 \pm 8.1^{*}$ \\
\hline
\end{tabular}

Values indicate the means $\pm S D$ in eight excised, cross-circulated canine hearts. $P_{1 \mathrm{~A}}$, $P_{2 \mathrm{~A}}, P_{3 \mathrm{~A}}$, and $P_{4 \mathrm{~A}}$ are the $\mathrm{h}-\mathrm{L}$ amplitude constants for Phases I, II, III, and IV, respectively. $P_{10}, P_{20}, P_{30}$, and $P_{40}$ are the $\mathrm{m}-\mathrm{E}$ amplitude constants for Phases I, II, III, and IV, respectively. $P_{1 \mathrm{~B}}, P_{2 \mathrm{~B}}, P_{3 \mathrm{~B}}$, and $P_{4 \mathrm{~B}}$ are the h-L nonzero asymptotes for Phases I, II, III, and IV, respectively. $P_{1^{\infty}}, P_{2^{\infty}}, P_{3^{\infty}}$, and $P_{4^{\infty}}$ are the m-E nonzero asymptotes for Phases I, II, III, and IV, respectively. 
${ }^{*} p<0.05$ vs. $33^{\circ} \mathrm{C}$.

${ }^{* *} p<0.001$ vs. $33^{\circ} \mathrm{C}$.

$\# p<0.05$ vs. $36^{\circ} \mathrm{C}$. 
Table 3. Goodness of half-logistic (h-L) and mono-exponential (m-E) fits for Phases I-IV in the isovolumic left ventricular (LV) pressure-time curves (PTCs) at $33^{\circ} \mathrm{C}, 36^{\circ} \mathrm{C}$, and $38^{\circ} \mathrm{C}$

\begin{tabular}{|c|c|c|c|}
\hline & \multicolumn{3}{|c|}{ Temperature $\left({ }^{\circ} \mathrm{C}\right)$} \\
\hline & 33 & 36 & 38 \\
\hline \multicolumn{4}{|l|}{ Phase I } \\
\hline $\mathrm{h}-\mathrm{L} r[Z]$ & $0.9995\left[4.1 \pm 0.6^{\star *}\right]$ & $0.9996\left[4.2 \pm 0.6^{* *}\right]$ & $0.9995\left[4.1 \pm 0.5^{\star \star}\right]$ \\
\hline $\mathrm{m}-\mathrm{E} r[Z]$ & $0.9976[3.4 \pm 0.3]$ & $0.9973[3.3 \pm 0.3]$ & $0.9973[3.3 \pm 0.3]$ \\
\hline h-L RMS $(\mathrm{mmHg})^{2}$ & $0231 \pm 0.382 \#$ & $0.172 \pm 0.279 \#$ & $0.103 \pm 0.106 \#$ \\
\hline $\mathrm{m}-\mathrm{E}$ RMS $(\mathrm{mmHg})^{2}$ & $0.754 \pm 1.027$ & $0.638 \pm 0.763$ & $0.427 \pm 0.339$ \\
\hline \multicolumn{4}{|l|}{ Phase II } \\
\hline $\mathrm{h}-\mathrm{L} r[Z]$ & $0.9997\left[4.3 \pm 0.3^{*}\right]$ & $0.9997\left[4.4 \pm 0.4^{*}\right]$ & $0.9997\left[4.4 \pm 0.3^{*}\right]$ \\
\hline $\mathrm{m}-\mathrm{E} r[Z]$ & $0.9986[3.6 \pm 0.2]$ & $0.9988[3.7 \pm 0.2]$ & $0.9989[3.7 \pm 0.3]$ \\
\hline h-L RMS $(\mathrm{mmHg})^{2}$ & $0.169 \pm 0.074 \#$ & $0.118 \pm 0.071 \#$ & $0.095 \pm 0.100 \#$ \\
\hline $\mathrm{m}-\mathrm{E}$ RMS $(\mathrm{mmHg})^{2}$ & $0.704 \pm 0.289$ & $0.478 \pm 0.300$ & $0.409 \pm 0.418$ \\
\hline \multicolumn{4}{|l|}{ Phase III } \\
\hline $\mathrm{h}-\mathrm{L} r[Z]$ & $0.9995\left[4.1 \pm 0.6^{\star *}\right]$ & $0.9996\left[4.2 \pm 0.5^{\star \star}\right]$ & $0.9995\left[4.2 \pm 0.4^{\star *}\right]$ \\
\hline $\mathrm{m}-\mathrm{E} r[Z]$ & $0.9983[3.5 \pm 0.5]$ & $0.9984[3.6 \pm 0.3]$ & $0.9983[3.5 \pm 0.2]$ \\
\hline h-L RMS $(\mathrm{mmHg})^{2}$ & $0.286 \pm 0.500 \#$ & $0.151 \pm 0.163 \#$ & $0.129 \pm 0.148 \#$ \\
\hline $\mathrm{m}-\mathrm{E}$ RMS $(\mathrm{mmHg})^{2}$ & $0.656 \pm 0.664$ & $0.456 \pm 0.242$ & $0.514 \pm 0.330$ \\
\hline \multicolumn{4}{|l|}{ Phase IV } \\
\hline $\mathrm{h}-\mathrm{L} r[Z]$ & $0.9997\left[4.5 \pm 0.7^{\star \star}\right]$ & $0.9997\left[4.5 \pm 0.9^{*}\right]$ & $0.9996\left[4.3 \pm 0.5^{\star \star}\right]$ \\
\hline $\mathrm{m}-\mathrm{E} r[Z]$ & $0.9983[3.5 \pm 0.3]$ & $0.9976[3.4 \pm 0.3]$ & $0.9975[3.3 \pm 0.2]$ \\
\hline h-L RMS $(\mathrm{mmHg})^{2}$ & $0.241 \pm 0.380 \#$ & $0.158 \pm 0.186 \#$ & $0.102 \pm 0.109 \#$ \\
\hline $\mathrm{m}-\mathrm{E}$ RMS $(\mathrm{mmHg})^{2}$ & $0.894 \pm 1.289$ & $0.625 \pm 0.419$ & $0.530 \pm 0.416$ \\
\hline
\end{tabular}

Values indicate the means $\pm S D$ in eight excised, cross-circulated canine hearts. $r$ is the correlation coefficient. The $r$ value indicates the mean following Z-transformation $(Z)$. RMS is the residual mean square.

${ }^{*} p<0.05$.

${ }^{* *} p<0.001$ vs. m-E Z.

$\# p<0.05$ vs. m-E RMS. 
Table 4. Temperature coefficients $\left(Q_{10}\right)$ of the reciprocal values of the half-logistic $(h-L)$ and mono-exponential $(m-E)$ time constants obtained by fitting using $h-L$ and $m-E$ functions for Phases I-IV in the isovolumic left ventricular (LV) pressure-time curve (PTC)

\begin{tabular}{rl}
\hline & \multicolumn{1}{c}{$Q_{10}$} \\
\hline Phase I & \\
$1 / P \tau_{1 \mathrm{~L}}$ & $1.3 \pm 0.4$ \\
$1 / P \tau_{1 \mathrm{E}}$ & $1.4 \pm 0.4$ \\
Phase II & \\
$1 / P \tau_{2 \mathrm{~L}}$ & $1.7 \pm 0.6$ \\
$1 / P \tau_{2 \mathrm{E}}$ & $1.8 \pm 0.9$ \\
Phase III & \\
$1 / P \tau_{3 \mathrm{~L}}$ & $2.2 \pm 0.7$ \\
$1 / P \tau_{3 \mathrm{E}}$ & $2.2 \pm 0.9$ \\
Phase IV & \\
$1 / P \tau_{4 \mathrm{~L}}$ & $2.4 \pm 0.5$ \\
$1 / P \tau_{4 \mathrm{E}}$ & $2.9 \pm 0.7$ \\
\hline
\end{tabular}

Values indicate the means $\pm S D$ in eight excised, cross-circulated canine hearts. $P \tau_{1 \mathrm{~L}}$, $P \tau_{2 \mathrm{~L}}, P \tau_{3 \mathrm{~L}}$, and $P \tau_{4 \mathrm{~L}}$ are the $\mathrm{h}-\mathrm{L}$ time constants for Phases I, II, III, and IV, respectively. $P \tau_{1 \mathrm{E}}, P \tau_{2 \mathrm{E}}, P \tau_{3 \mathrm{E}}$, and $P \tau_{4 \mathrm{E}}$ are the $\mathrm{m}-\mathrm{E}$ time constants for Phases I, II, III, and IV, respectively. 


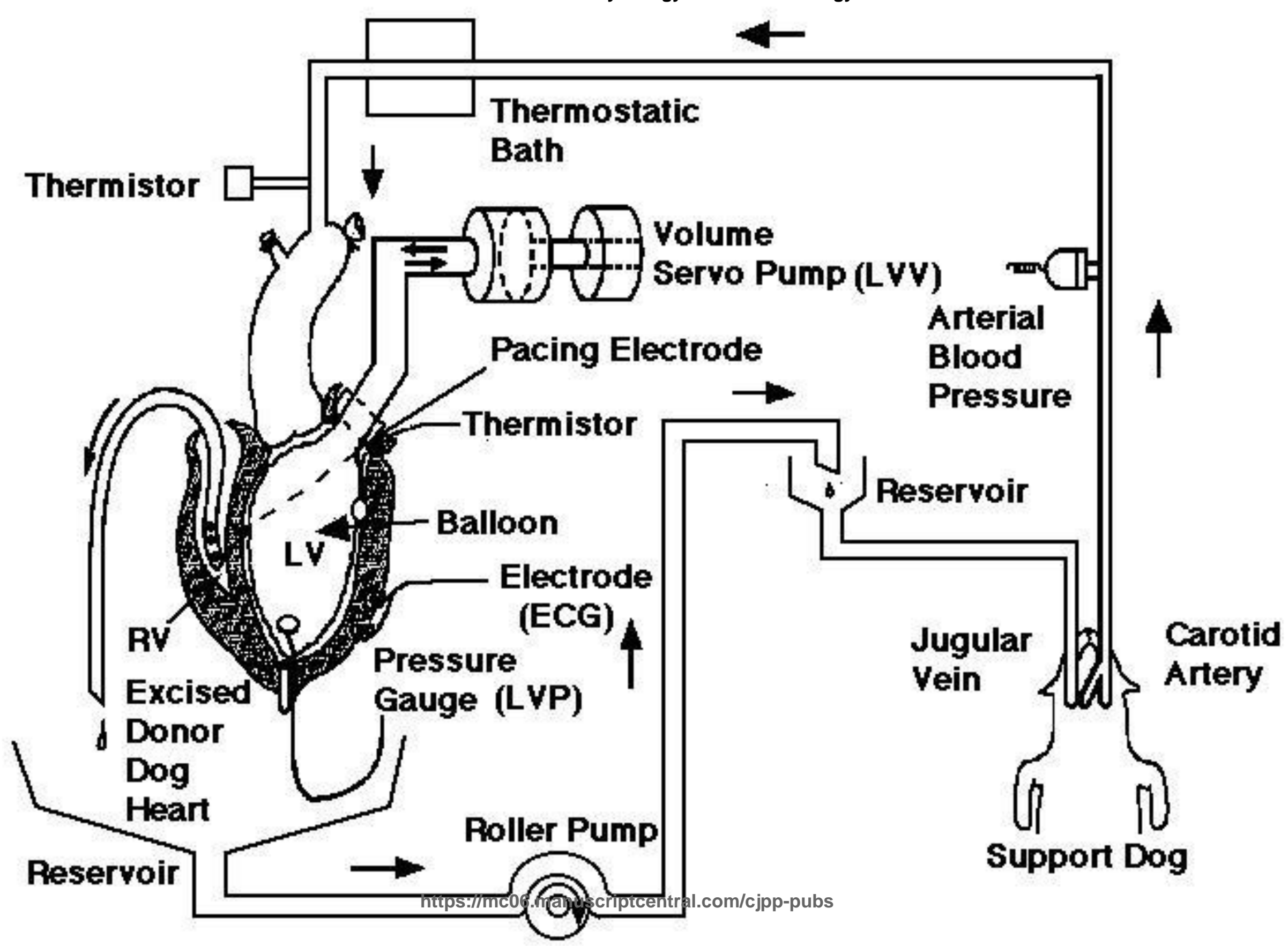




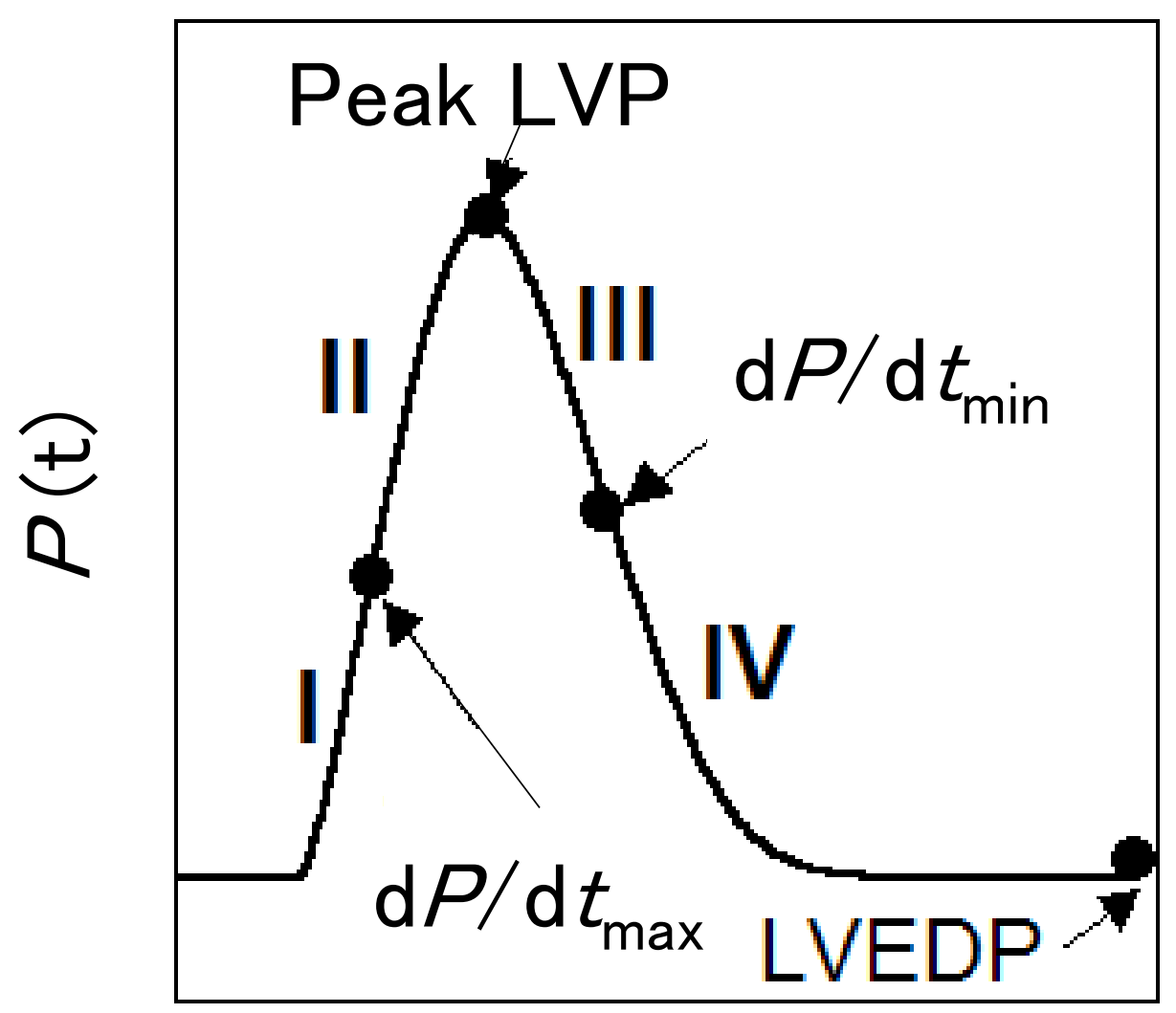

Time 


\section{Phase I}

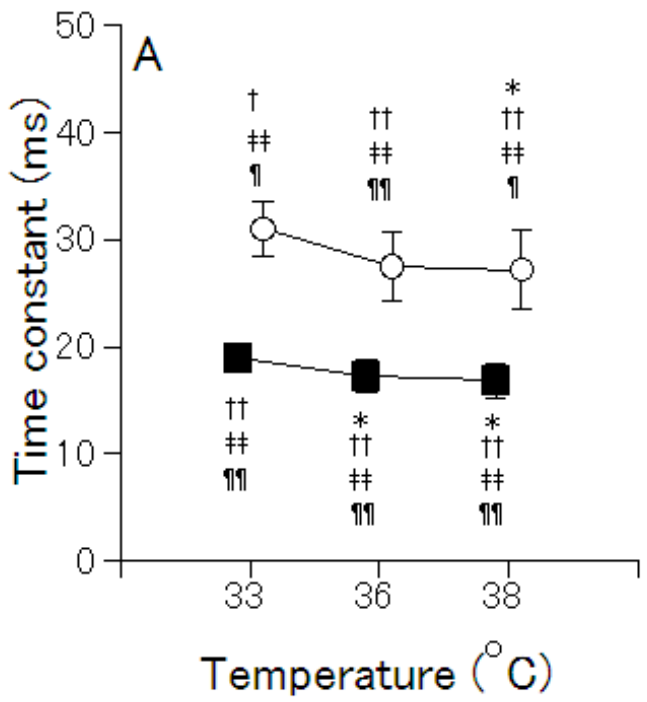

Phase III

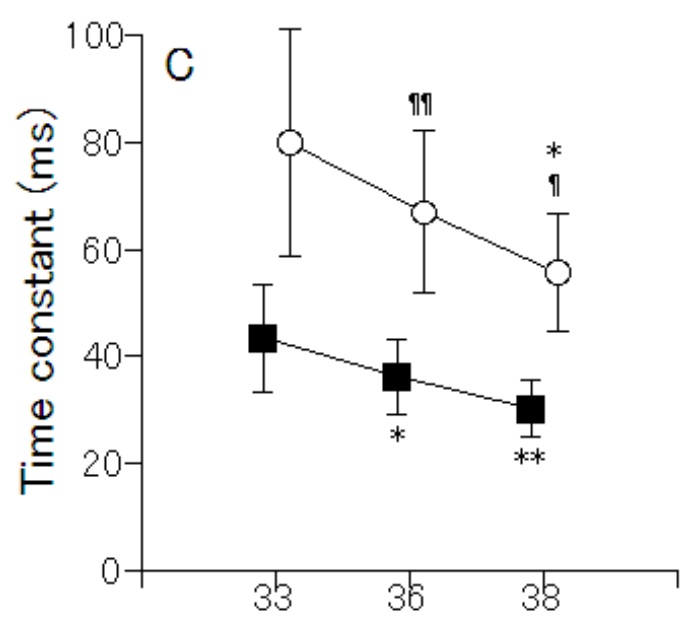

Phase II

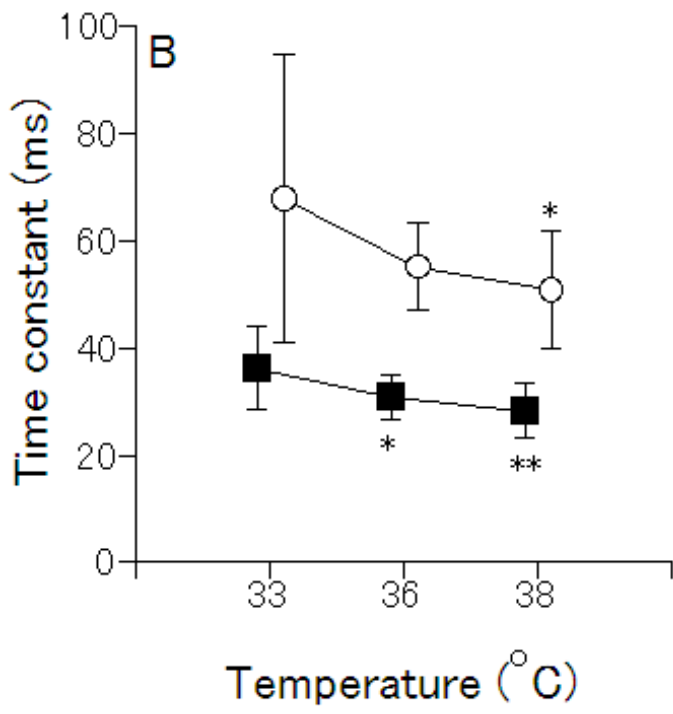

Phase IV

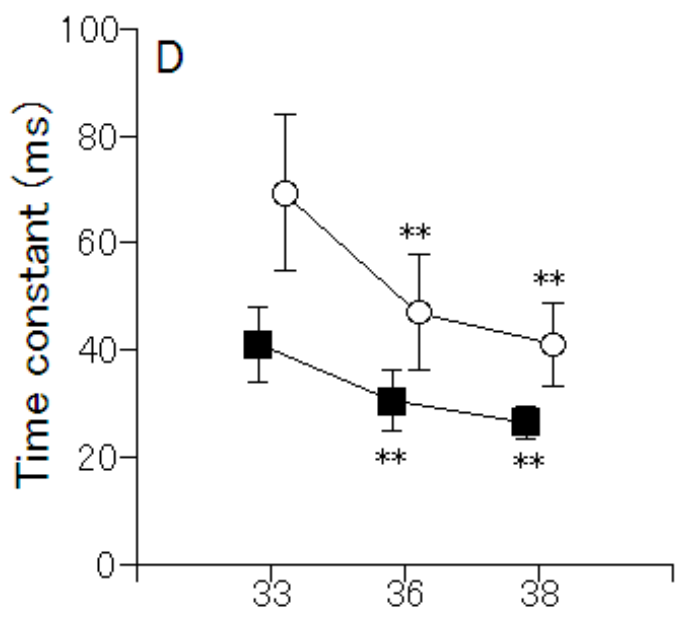

Temperature $\left({ }_{\mathrm{https}: / / \mathrm{mc} 06 \text {. manuscriptcentral.com/cjpp-pubs }}^{\text {Temperature }}\left({ }^{\circ} \mathrm{C}\right)\right.$ 